\title{
Immunophenotypic overlap between adenoid cystic carcinoma and collagenous spherulosis of the breast: potential diagnostic pitfalls using myoepithelial markers
}

\author{
Joseph T Rabban ${ }^{1}$, Rebecca S Swain ${ }^{1}$, Charles J Zaloudek ${ }^{1}$, Donald R Chase ${ }^{2}$ and \\ Yunn Yi Chen ${ }^{1}$ \\ ${ }^{1}$ Department of Pathology, University of California, San Francisco, CA, USA and ${ }^{2}$ California Tumor Tissue \\ Registry, Loma Linda, CA, USA
}

\begin{abstract}
Adenoid cystic carcinoma of the breast is a rare neoplasm whose cribriform architecture may mimic invasive cribriform carcinoma, cribriform ductal carcinoma in situ, and collagenous spherulosis. The diagnosis may be even more challenging in needle core biopsies. Immunohistochemical expression of p63 and c-kit distinguishes adenoid cystic carcinoma from invasive cribriform carcinoma and ductal carcinoma in situ. A formal comparison of the immunophenotype of adenoid cystic carcinoma to collagenous spherulosis has not been reported. Of concern is the overlap in myoepithelial markers between these two entities. Both may express S100, smooth muscle actin, and p63. This overlap may cause diagnostic confusion yet is under-emphasized in the literature. The expression profile of newer myoepithelial markers has not been studied in this setting. We evaluated smooth muscle actin, p63, calponin, smooth muscle myosin heavy chain, as well as c-kit, in nine cases of cribriform pattern adenoid cystic carcinoma of the breast in comparison to 12 cases of collagenous spherulosis. Both entities strongly expressed p63 and smooth muscle actin; in adenoid cystic carcinoma, the basaloid myoepithelial-like tumor cells expressed these markers, but the ductular epithelial cells did not. Neither calponin nor smooth muscle myosin heavy chain was expressed in adenoid cystic carcinoma but both were strongly expressed in collagenous spherulosis. Whereas the ductular epithelial cells of adenoid cystic carcinoma were positive for c-kit in all cases, collagenous spherulosis was negative for c-kit. Positive p63 expression by a cribriform breast lesion is not sufficiently specific to confirm a diagnosis of adenoid cystic carcinoma. A broader panel that includes calponin or smooth muscle myosin heavy chain and c-kit is required to exclude collagenous spherulosis in settings in which the distinctive morphologic features that separate these entities are not conspicuously present. Reliance on p63 or smooth muscle actin alone poses a potential diagnostic pitfall in evaluating cribriform breast lesions.
\end{abstract}

Modern Pathology (2006) 19, 1351-1357. doi:10.1038/modpathol.3800658; published online 30 June 2006

Keywords: adenoid cystic carcinoma; collagenous; spherulosis; myoepithelium; p63; CD117; breast

Cribriform architecture characterizes a broad spectrum of benign and malignant proliferations in the breast, chiefly invasive cribriform carcinoma, ductal carcinoma in situ, adenoid cystic carcinoma, and collagenous spherulosis. The differential diagnosis can be especially challenging in needle core biopsies. Among these entities, adenoid cystic carcinoma is unique from a morphologic and clinical

Correspondence: Dr JT Rabban, MD, MPH, Department of Pathology, University of California, San Francisco, 505 Parnassus Avenue, Box 0102, San Francisco, CA 94143, USA.

E-mail: joseph.rabban@ucsf.edu

Received 11 May 2006; revised 6 June 2006; accepted 7 June 2006; published online 30 June 2006 perspective. The cribriform variant consists of a dual population of tumor cells. It is composed primarily of myoepithelial-like cells that form a sieve-like pattern of pseudocysts that contain basement membrane material. The second, a less numerous population, consists of ductal epithelial cells that form narrow lumens embedded throughout the lesion. ${ }^{1-6}$ Despite the fact that adenoid cystic carcinoma generally does not express estrogen or progesterone receptors and does not show HER2 gene amplification, it typically behaves favorably and should be distinguished from invasive cribriform carcinoma. ${ }^{3}$ Several studies show that immunoexpression of p63 by the myoepithelial-like tumor cells and of c-kit by the ductular epithelial tumor 
cells of adenoid cystic carcinoma reliably distinguishes it from both cribriform carcinoma and ductal carcinoma in situ. ${ }^{1-3,7,8}$ These studies propose that in the evaluation of cribriform breast lesions, p63, and c-kit can be used adjunctively to confirm a diagnosis of adenoid cystic carcinoma. This proposal is potentially problematic because collagenous spherulosis remains in the differential diagnosis and is known to express p63, as well as other myoepithelial markers expressed by adenoid cystic carcinoma, including smooth muscle actin and s100. ${ }^{9-11}$ Furthermore, c-kit expression by collagenous spherulosis has not been studied. Therefore, the diagnostic specificity of p63 and c-kit for adenoid cystic carcinoma remains incompletely tested; cases of collagenous spherulosis could be misdiagnosed based on immunohistochemistry when definitive diagnostic morphologic features are inconspicuous or when the sample size is limited, such as in needle core biopsies. In this study, we evaluated a range of myoepithelial markers, including smooth muscle actin, smooth muscle myosin heavy chain, calponin and p63, as well as c-kit, in cribriform pattern adenoid cystic carcinoma of the breast and in collagenous spherulosis. We demonstrate potential pitfalls of using certain myoepithelial markers in this setting and propose a more specific immunohistochemical approach to this differential diagnosis of adenoid cystic carcinoma vs collagenous spherulosis.

\section{Materials and methods}

Slides from formalin-fixed, paraffin-embedded breast tissue were retrieved from the surgical pathology and consultation files of the University of California, San Francisco and the California Tumor Tissue Registry, Loma Linda, CA. Nine examples of cribriform pattern adenoid cystic carcinoma of the breast and 12 cases of collagenous spherulosis were evaluated. All cases were from excisional specimens. The slides of adenoid cystic carcinoma cases selected for immunostaining showed grade I of III architecture (no solid areas) using both the Kleer and Oberman criteria for adenoid cystic carcinoma and the more general Nottingham grading criteria. ${ }^{12,13}$ Collagenous spherulosis was defined according to the criteria of Clement et al. ${ }^{9}$ All cases of collagenous spherulosis were incidental findings within benign epithelial proliferations, including adenosis and mild usual hyperplasia; none of the cases involved epithelial atypia or carcinoma, either in situ or invasive. Immunoreactivity for smooth muscle actin, p63, smooth muscle myosin heavy chain, calponin, and c-kit (CD117) was assessed in all cases. Table 1 lists the details of the antibodies used. Tissue sections for calponin and smooth muscle myosin heavy chain were initially digested in $0.005 \%$ trypsin for $15 \mathrm{~min}$. Microwave antigen retrieval was performed on deparaffinized and rehydrated sections. This was performed in $10 \mathrm{mM}$ citrate buffer for calponin, smooth muscle actin, and smooth muscle myosin heavy chain, and in DAKO Target Retrieval Solution for 10 min for p63 and CD117. Endogenous peroxidase was blocked by incubating sections in $3 \%$ hydrogen peroxide for $10 \mathrm{~min}$. Sections were then sequentially incubated with primary antibody for $30 \mathrm{~min}$, DAKO LSAB LINK antibody for $10 \mathrm{~min}$, peroxidase-conjugated streptavidin for $10 \mathrm{~min}$, and DAKO Liquid DAB for 5 min. Normal breast myoepithelium served as a positive internal control in each case for p63, smooth muscle actin, smooth muscle myosin heavy chain, and calponin. For c-kit, the positive internal controls were stromal mast cells and normal breast epithelium, which showed a patchy distribution of expression in some acini and ducts. ${ }^{7,14}$ Positive staining for each antibody is defined in Table 1.

\section{Results}

\section{Collagenous Spherulosis}

The myoepithelial cells surrounding the basement membrane deposits in collagenous spherulosis expressed all four myoepithelial markers (Table 2). The cytoplasmic pattern of smooth muscle actin, smooth muscle myosin heavy chain, and calponin was uniform and strong in each case (Figure 1). The ring-like peripheral circumscription of each spherule by the myoepithelial cells was well defined by each of these cytoplasmic myoid markers. Myoepithelial nuclear expression of p63 was also strong in each case. Because the number of myoepithelial cells forming the ring-like lesion is small and is mostly composed of myoepithelial cell cytoplasm stretched around the basement membrane deposits,

Table 1 Immunohistochemical stains

\begin{tabular}{llrl}
\hline Antibody & Vendor & Dilution & Staining pattern \\
\hline c-kit (CD117) & Dako & $1: 50$ & $\begin{array}{l}\text { Membrane or } \\
\text { cytoplasmic }\end{array}$ \\
Calponin & Dako & $1: 500$ & Cytoplasmic \\
p63 & Lab Vision & $1: 50$ & Nuclear \\
Smooth muscle actin & Dako & $1: 100$ & Cytoplasmic \\
Smooth muscle myosin & Dako & $1: 200$ & Cytoplasmic \\
\hline
\end{tabular}

Table 2 Results of immunohistochemical staining

\begin{tabular}{lcc}
\hline Antibody & $\begin{array}{c}\text { Collagenous spherulosis } \\
\text { (\% of cases) }\end{array}$ & $\begin{array}{c}\text { ACC (\% of } \\
\text { cases) }\end{array}$ \\
\hline $\begin{array}{l}\text { Smooth muscle actin } \\
\text { p63 }\end{array}$ & $\begin{array}{c}\text { Positive }(100 \%) \\
\text { Positive }(100 \%)\end{array}$ & $\begin{array}{c}\text { Positive }(100 \%) \\
\text { Positive }(100 \%)\end{array}$ \\
myosin muscle & Positive (100\%) & Negative $(100 \%)$ \\
$\begin{array}{l}\text { Calponin } \\
\text { c-kit (CD117) }\end{array}$ & Positive (100\%) & Negative $(100 \%)$ \\
& Negative $(100 \%)$ & Positive $(100 \%)$
\end{tabular}



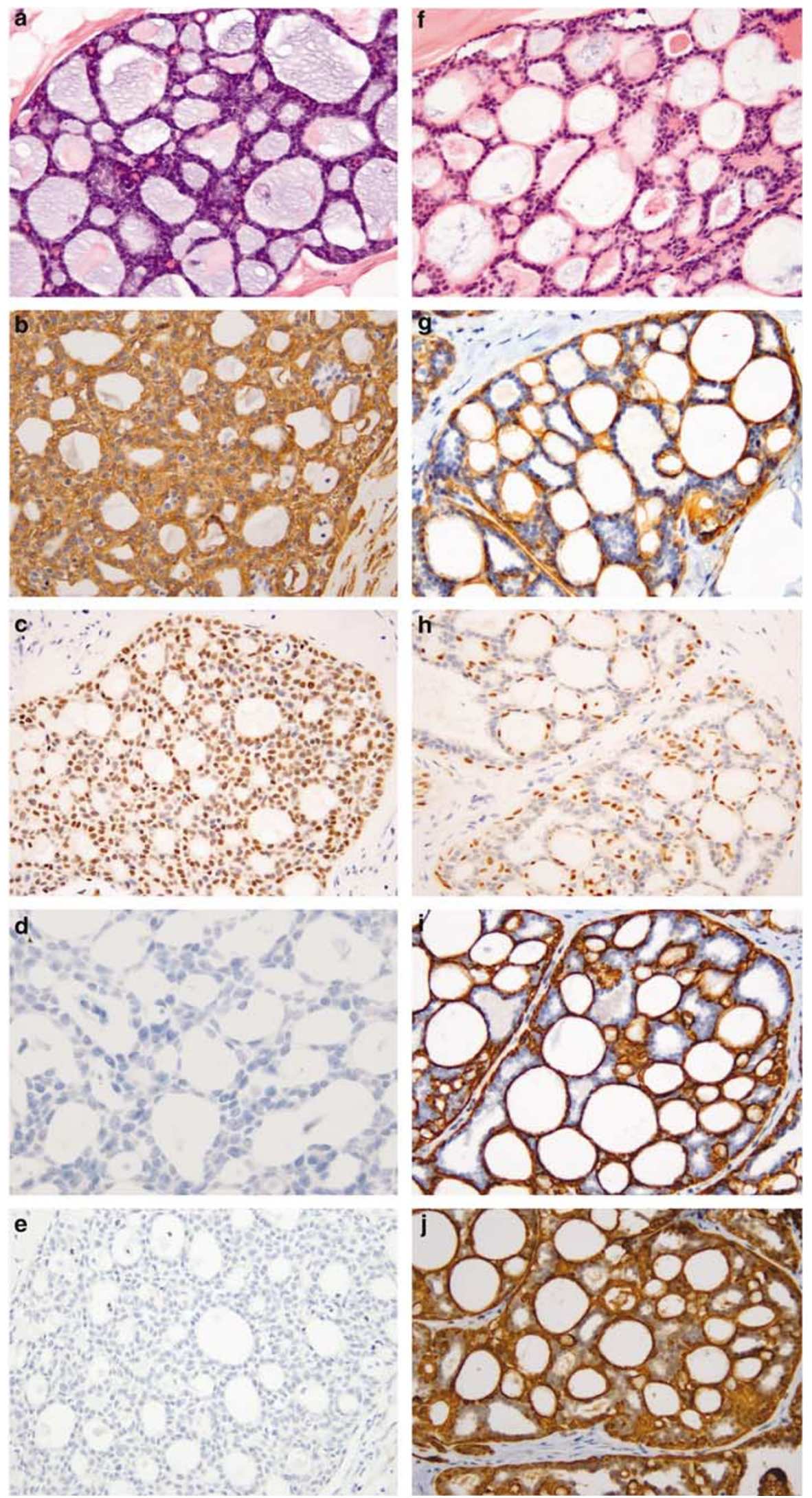

Figure 1 Comparison of hematoxylin and eosin stain in adenoid cystic carcinoma (a) vs collagenous spherulosis (f); smooth muscle actin in adenoid cystic carcinoma (b) vs collagenous spherulosis (g); p63 in adenoid cystic carcinoma (c) vs collagenous spherulosis (h); smooth muscle myosin heavy chain in adenoid cystic carcinoma (d) vs collagenous spherulosis (i); calponin in adenoid cystic carcinoma (e) vs collagenous spherulosis (j). 

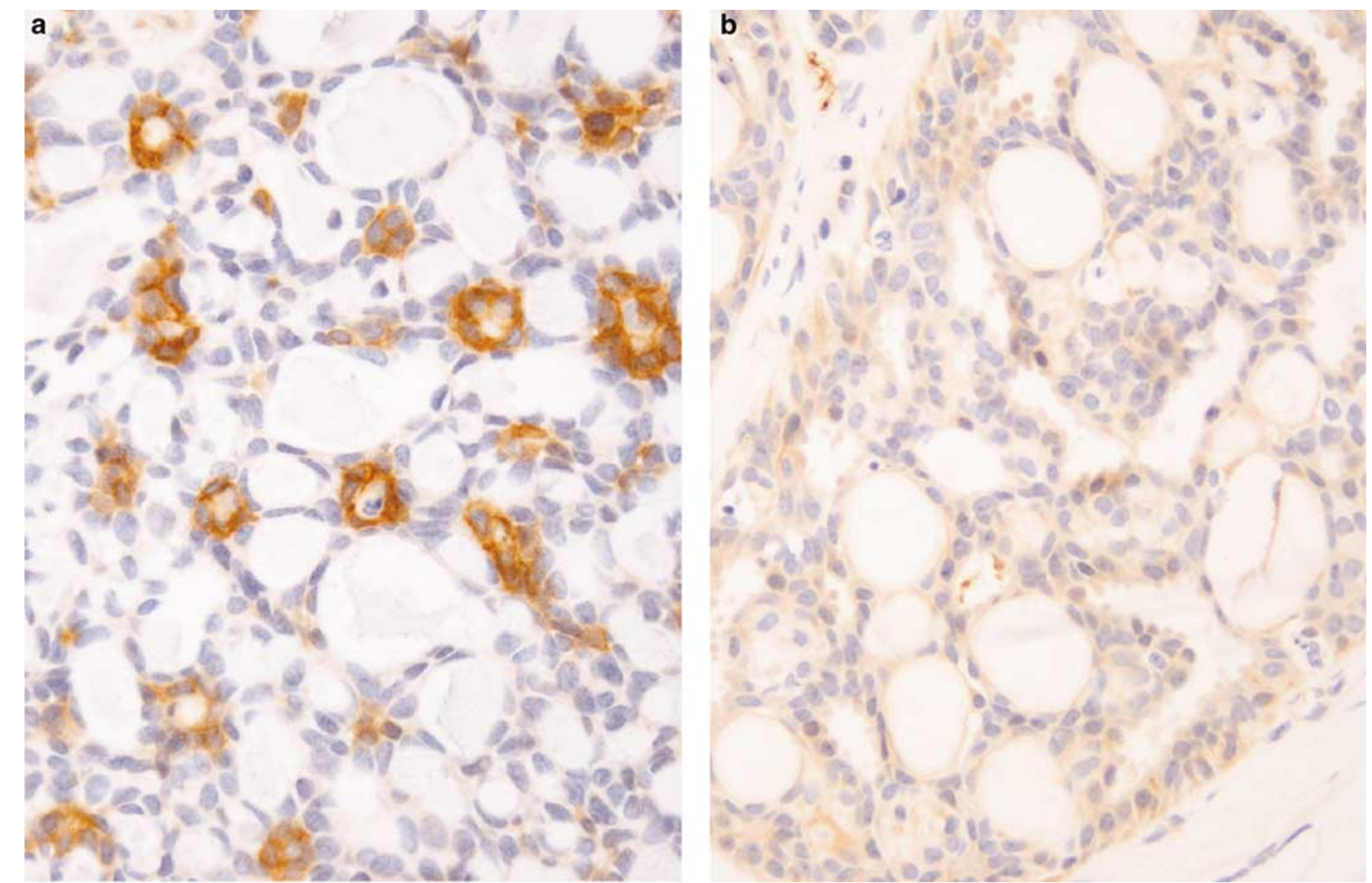

Figure 2 c-kit marks the ductular epithelium in adenoid cystic carcinoma (a) but is not expressed by the myoepithelial cells of collagenous spherulosis (b).

the expression of p63 is not as noticeable at low power as the cytoplasmic markers are. Thus, careful inspection of the nuclei at higher power is needed for evaluating p63 in collagenous spherulosis. In rare cases (Figure 3), the myoepithelial component was prominent, whereas the background epithelium was less conspicuous, yielding a p63 staining pattern that was more cribriform than ring-like in distribution. The epithelial cell population within which the spherules and their myoepithelial coating were embedded did not express any myoid marker. c-kit was not expressed by any of the myoepithelial cells in any case of collagenous spherulosis (Figure 2).

\section{Adenoid Cystic Carcinoma}

The myoepithelial-like cell population of adenoid cystic carcinoma expressed both smooth muscle actin and p63 but neither calponin nor smooth muscle myosin heavy chain in any case (Figure 1). The nuclear staining pattern of p63 was strong and diffuse in all cases. Smooth muscle actin produced a uniform strong cytoplasmic signal. The low-magnification distribution of these stains mimicked the cribriform pattern of the lesion itself. The ductular epithelial population in the tumor did not express any myoepithelial marker but did demonstrate strong cytoplasmic c-kit expression in each case (Figure 2). These ductules were often few in number and sparsely distributed in a random manner throughout each tumor, making them sometimes difficult to recognize on low magnification of hematoxylin- and eosin-stained sections. Higher magnification and staining for c-kit facilitated identification of the ductules.

\section{Discussion}

This study demonstrates a myoepithelial immunophenotypic overlap between cribriform pattern adenoid cystic carcinoma of the breast and collagenous spherulosis that could lead to diagnostic pitfalls in evaluating cribriform lesions of the breast. Our results show that both smooth muscle actin and p63 are expressed by both entities and therefore do not distinguish the two. This study reveals, however, that other myoepithelial markers, calponin and smooth muscle myosin heavy chain, are expressed only by collagenous spherulosis and thus can be used to distinguish it from adenoid cystic carcinoma. The converse is shown for c-kit expression. This constellation of findings is relevant because cribriform lesions in the breast may be challenging to diagnose by routine morphology, especially in core needle biopsies, and recent studies recommend an 
immunohistochemical approach to complement morphologic impressions. ${ }^{1,3}$ The overlap in immunophenotype that we report here and its diagnostic implications are not emphasized in the literature.

Cribriform growth is commonly encountered in a variety of breast lesions. The term cribriform derives from the Latin cribrum, meaning sieve-like or pierced with small holes. ${ }^{15}$ The term cribriform was used as a histological architectural description in the breast as early as 1933 in describing growth patterns of ductal carcinoma in situ. ${ }^{16}$ Currently, the term is used to refer to a proliferation that resembles a sieve, in which the proliferation is perforated by rounded spaces or fenestrations. ${ }^{17}$ It is not necessarily implied that the spaces are the lumens of glands or are epithelial lined cysts. In the breast, invasive cribriform carcinoma, cribriform ductal carcinoma in situ, adenoid cystic carcinoma, and collagenous spherulosis may all have a sieve-like architecture on low-power magnification. Attention to subtle morphologic features, well summarized in detail elsewhere, ${ }^{5,9,10,18,19}$ often allows these entities to be distinguished using routinely stained sections alone, but these features may not always be appreciated in needle core biopsies or in small excisions. In the case of cribriform type of adenoid cystic carcinoma, the diagnosis requires the presence of two cell populations: basaloid myoepithelial-like cells, comprising the majority of the tumor, form the cribriform proliferation itself and epithelial cells form small tight ductules variably scattered throughout the tumor. The cribriform spaces are pseudoglandular spaces formed within the myoepithelial tumor cell proliferation and are often filled with eosinophilic or basophilic basement membrane material..$^{5,12,18,20-22}$ Cytologically, the ductular epithelial cells are columnar to cuboidal and usually have a modest amount of eosinophilic cytoplasm, whereas the more numerous myoepithelial-like cells are round and have scanty basophilic cytoplasm. Recognizing the ductular epithelial cells can be difficult for several reasons. There may be relatively few ductular structures in the sample; the ductules may be small in diameter, with nearly imperceptible lumens; or the sample size itself may be limited, particularly in core biopsies. If these ductular structures are missed, the lesion could be misinterpreted as invasive cribriform carcinoma or ductal carcinoma in situ. Morphologic and immunohistochemical features helpful in this differential diagnosis have been addressed by others. ${ }^{1}$ If the pseudoglandular spaces of adenoid cystic carcinoma are prominent, owing to abundant cylindromatous basement membrane deposits, then the lesion could be mistaken for collagenous spherulosis. In collagenous spherulosis, a well-defined eosinophilic cuticle, representing myoepithelial cell cytoplasm, typically forms a ring-like structure encompassing eosinophilic basement membrane material, or less commonly basophilic mucinous material. ${ }^{9-11}$ Difficulty in recognizing this entity may arise if the cuticle is inconspicuous or if the lesion is embedded in an epithelial proliferation such as ductal hyperplasia or lobular neoplasia. An associated epithelial proliferation may contribute to confusion as adenoid cystic carcinoma. Although collagenous spherulosis is typically an incidental microscopic finding and adenoid cystic carcinoma typically forms a mass, this difference may not be easily appreciated in cases for which limited amounts of tissue are available. Therefore, on rare occasions in which the distinctive morphologic features of these two entities are not easily recognizable, immunohistochemistry may be a useful diagnostic adjunct.

Recently, two immunohistochemical features of adenoid cystic carcinoma have been documented: expression of p63, a marker of stem cell or myoepithelial differentiation, and expression of c-kit, a transmembrane tyrosine kinase receptor protein; expression of these markers is similar in adenoid cystic carcinoma arising in the breast and in the head and neck. ${ }^{1-3,23-25}$ The myoepithelial-like tumor cells express p63 in a nuclear pattern, whereas the ductular epithelial cells do not express p63. The converse is seen for c-kit expression: there is cytoplasmic and membrane staining of ductular epithelium but no staining of the myoepithelial-like cells. ${ }^{1-3,7,8}$ Invasive cribriform carcinoma does not express c-kit and only a small proportion of ductal carcinoma in situ expresses c-kit, typically highgrade lesions that do not demonstrate cribriform growth. ${ }^{1,7,26,27}$ Neither expresses p63. ${ }^{1}$ Based on these observations, it has been proposed that positive staining for p63 and c-kit in a cribriform lesion of the breast supports the diagnosis of adenoid cystic carcinoma.

Our findings raise an important caveat to such a proposal. Although positive p63 and c-kit staining in the tumor cells excludes invasive and in situ carcinoma, the diagnosis of collagenous spherulosis is not necessarily excluded. Before our study, c-kit expression had not been evaluated in collagenous spherulosis, so the specificity of this marker for adenoid cystic carcinoma was not proven. More importantly, we show that p63 is expressed by collagenous spherulosis, a finding noted previously. ${ }^{10}$ The same holds true for smooth muscle actin expression by both entities. Therefore, it is inaccurate to rely solely on a positive p63 stain to diagnose a cribriform breast lesion as adenoid cystic carcinoma. It is helpful to consider a subtle difference in the distribution of p63-positive cells in these two entities. We observed that the vast majority of the tumor cells in cribriform adenoid cystic carcinoma expressed p63, emphasizing the cribriform pattern. Only the c-kit-positive ductular epithelial cells are p63 negative. In contrast, p63 expression in most of our cases of collagenous spherulosis resulted in a ring-like pattern, corresponding to the ring-like arrangement of myoepithelial cells around the basement membrane deposits; 

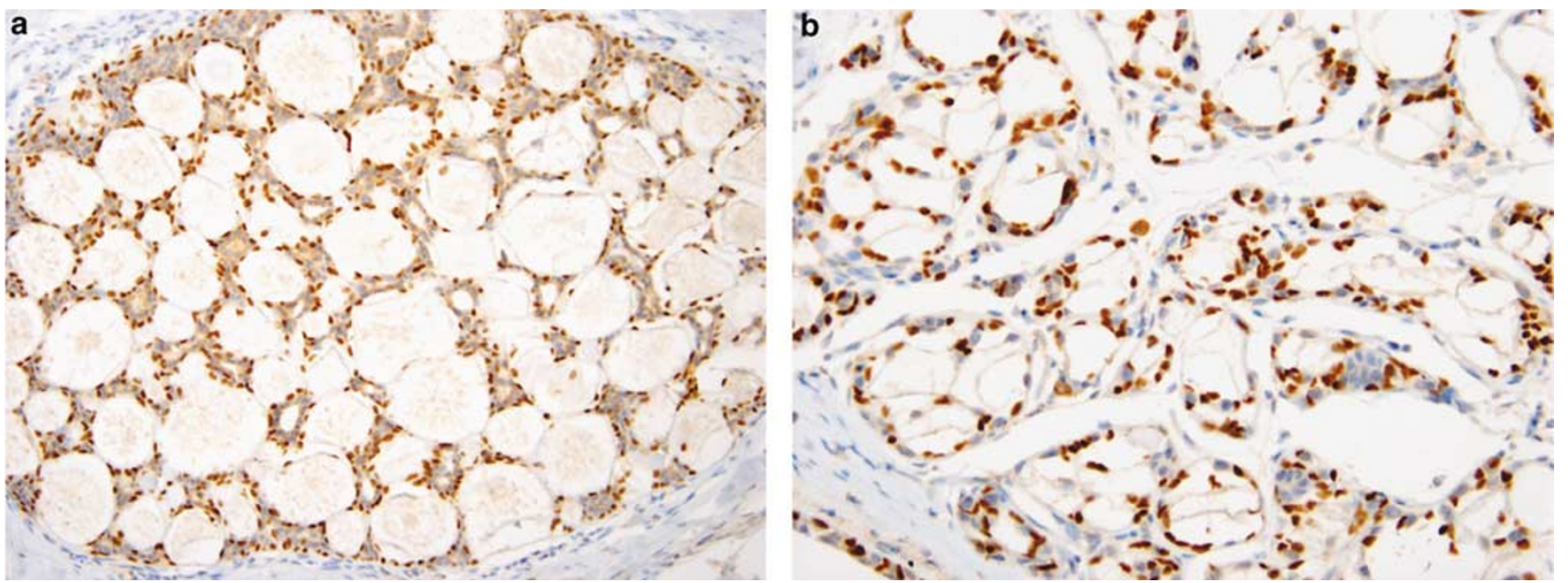

Figure 3 Cribriform-like pattern of p63 immunostaining generated by a case of collagenous spherulosis with a prominence of cribriform spaces and a paucity of ductal epithelium (a). A similar example of collagenous spherulosis with unusually numerous myoepithelial cell nuclei, highlighted by p63 (b). Both of these p63 stains could be misinterpreted as consistent with adenoid cystic carcinoma.

typically, only a few myoepithelial nuclei were present in each ring. As collagenous spherulosis is typically embedded in an epithelial proliferation, most of the cells present are epithelial and do not express p63. Recognizing these two patterns, cribriform vs ring-like, can help avoid misinterpreting the stains. Rarely, however, we noted cases of collagenous spherulosis in which the myoepithelium was more cellular, whereas the presence of background epithelium was diminished (Figure 3); the resulting distribution of p63-positive cells mimics a cribriform pattern rather than a ring-like pattern. Such cases could be misinterpreted as adenoid cystic carcinoma if only a p63 stain had been performed.

Regarding c-kit, it was previously unknown whether or not this marker is expressed by the myoepithelial cells of collagenous spherulosis. Our study demonstrates that it is not expressed and therefore does distinguish adenoid cystic carcinoma from collagenous spherulosis. Because these c-kitpositive ductular structures are often only sparsely present in the cribriform pattern of adenoid cystic carcinoma, they may not be well represented in core needle biopsies. Therefore, a negative stain for c-kit in a needle biopsy does not necessarily exclude this diagnosis and further evaluation of the basaloid cells by myoepithelial markers is warranted.

The additional myoepithelial markers that we recommend based on this study are calponin and smooth muscle myosin heavy chain, which were expressed in collagenous spherulosis but not in adenoid cystic carcinoma. These results were uniform in all cases tested. There was no ambiguity in stain interpretation; the staining was clearly either positive or negative. Thus, we propose that the immunohistochemical approach to distinguishing collagenous spherulosis from adenoid cystic carcinoma should not rely solely on p63 or c-kit but should include calponin or smooth muscle myosin heavy chain as well. The biologic basis for the differential myoepithelial expression pattern in these two lesions is not readily apparent. It has been suggested that the basaloid myoepithelial-like tumor cells of adenoid cystic carcinoma are modified stem cells or indifferent pluripotential cells capable of differentiating into epithelial or myoepithelial cells. ${ }^{18}$ The partial myoepithelial immunophenotype we observed is compatible with the view that expression of calponin and smooth muscle myosin heavy chain is a feature of the fully differentiated myoepithelial cell in the breast. ${ }^{28-30}$ Further investigation into the molecular and genetic characteristics of this unique cell type are needed to elucidate how the clinical behavior of adenoid cystic carcinoma differs from that of most breast cancers which lack estrogen and progesterone receptors and HER2 gene amplification. ${ }^{3}$

In summary, this is the first formal comparison of myoepithelial immunophenotypes of adenoid cystic carcinoma and collagenous spherulosis in the breast. Pathologists should be aware of the overlap of p63 and smooth muscle actin expression between these entities. In the unusual setting in which immunohistochemistry is needed to distinguish these entities, a panel should also include calponin or smooth muscle myosin heavy chain, both of which we demonstrate to reliably distinguish collagenous spherulosis from cribriform pattern adenoid cystic carcinoma of the breast. Finally, we establish that c-kit, known to be a sensitive marker of adenoid cystic carcinoma, is not expressed in collagenous spherulosis.

\section{Acknowledgement}

This study was presented in part at the United States and Canadian Academy of Pathologists annual meeting in March 2005, San Antonio, TX. 


\section{Conflict of interest}

There are no conflicts of interest to disclose by any of the authors.

\section{References}

1 Mastropasqua MG, Maiorano E, Pruneri G, et al. Immunoreactivity for c-kit and p63 as an adjunct in the diagnosis of adenoid cystic carcinoma of the breast. Mod Pathol 2005;18:1277-1282.

2 Crisi GM, Marconi SA, Makari-Judson G, et al. Expression of c-kit in adenoid cystic carcinoma of the breast. Am J Clin Pathol 2005;124:733-739.

3 Azoulay S, Lae M, Freneaux P, et al. KIT is highly expressed in adenoid cystic carcinoma of the breast, a basal-like carcinoma associated with a favorable outcome. Mod Pathol 2005;18:1623-1631.

4 Trendell-Smith NJ, Peston D, Shousha S. Adenoid cystic carcinoma of the breast: a tumour commonly devoid of oestrogen receptors and related proteins. Histopathology 1999;35:241-248.

5 Zaloudek C, Oertel YC, Orenstein JM. Adenoid cystic carcinoma of the breast. Am J Clin Pathol 1984;81: 297-307.

6 Peters GN, Wolff M. Adenoid cystic carcinoma of the breast. Report of 11 new cases: review of the literature and discussion of biological behavior. Cancer 1983; 52:680-686.

7 Ulivi P, Zoli W, Medri L, et al. c-kit and SCF expression in normal and tumor breast tissue. Breast Cancer Res Treat 2004;83:33-42.

8 Hill PA. c-kit expression in adenoid cystic carcinoma of the breast. Pathology 2004;36:362-364.

9 Clement PB, Young RH, Azzopardi JG. Collagenous spherulosis of the breast. Am J Surg Pathol 1987;11: 411-417.

10 Resetkova E, Albarracin C, Sneige N. Collagenous spherulosis of breast: morphologic study of 59 cases and review of the literature. Am J Surg Pathol 2006; 30:20-27.

11 Mooney EE, Kayani N, Tavassoli FA. Spherulosis of the breast. A spectrum of municous and collagenous lesions. Arch Pathol Lab Med 1999;123: 626-630.

12 Kleer CG, Oberman HA. Adenoid cystic carcinoma of the breast: value of histologic grading and proliferative activity. Am J Surg Pathol 1998;22:569-575.

13 Elston CW, Ellis IO. Pathological prognostic factors in breast cancer. I. The value of histological grade in breast cancer: experience from a large study with long-term follow-up. Histopathology 1991;19:403-410.

14 Yared MA, Middleton LP, Meric F, et al. Expression of c-kit proto-oncogene product in breast tissue. Breast J 2004;10:323-327.

15 Newman Dorland WA (ed). Dorland's Illustrated Medical Dictionary, 28th edn. WB Saunders Company: Philadelphia, 1994.
16 Schultz-Brauns O. Die Geschwulste der brustdruse. In: Lubarsch O, Henke F (eds). Handbuch der Speziellen Pathologischen Anatomie und Histologie, Vol. VII. Verag Von Julius Springer: Berlin, 1933, pp 290-292.

17 Rosen PP. Breast Pathology. Lippincott Williams \& Wilkins: Philadelphia, 2001, p 273.

18 Lamovec J, Us-Krasovec M, Zidar A, et al. Adenoid cystic carcinoma of the breast: a histologic, cytologic, and immunohistochemical study. Semin Diagn Pathol 1989;6:153-164.

19 Ro JY, Silva EG, Gallager HS. Adenoid cystic carcinoma of the breast. Hum Pathol 1987;18:1276-1281.

20 Anthony PP, James PD. Adenoid cystic carcinoma of the breast: prevalence, diagnostic criteria, and histogenesis. J Clin Pathol 1975;28:647-655.

21 Qizilbash AH, Patterson MC, Oliveira KF. Adenoid cystic carcinoma of the breast. Light and electron microscopy and a brief review of the literature. Arch Pathol Lab Med 1977;101:302-306.

22 Friedman BA, Oberman HA. Adenoid cystic carcinoma of the breast. Am J Clin Pathol 1970;54:1-14.

23 Mino M, Pilch BZ, Faquin WC. Expression of KIT (CD117) in neoplasms of the head and neck: an ancillary marker for adenoid cystic carcinoma. Mod Pathol 2003;16:1224-1231.

24 Edwards PC, Bhuiya T, Kelsch RD. C-kit expression in the salivary gland neoplasms adenoid cystic carcinoma, polymorphous low-grade adenocarcinoma, and monomorphic adenoma. Oral Surg Oral Med Oral Pathol Oral Radiol Endod 2003;95:586-593.

25 Edwards PC, Bhuiya T, Kelsch RD. Assessment of p63 expression in the salivary gland neoplasms adenoid cystic carcinoma, polymorphous low-grade adenocarcinoma, and basal cell and canalicular adenomas. Oral Surg Oral Med Oral Pathol Oral Radiol Endod 2004;97:613-619.

26 Diallo R, Rody A, Jackisch C, et al. C-KIT expression in ductal carcinoma in situ of the breast: co-expression with HER-2/neu. Hum Pathol 2006;37:205-211.

27 Tsuda H, Morita D, Kimura M, et al. Correlation of KIT and EGFR overexpression with invasive ductal breast carcinoma of the solid-tubular subtype, nuclear grade 3 , and mesenchymal or myoepithelial differentiation. Cancer Sci 2005;96:48-53.

28 Lazard D, Sastre X, Frid MG, et al. Expression of smooth muscle-specific proteins in myoepithelium and stromal myofibroblasts of normal and malignant human breast tissue. Proc Natl Acad Sci USA 1993; 90:999-1003.

29 Wang NP, Wan BC, Skelly M. Antibodies to novel myoepithelium-associated proteins distinguish benign lesions and in situ carcinoma from invasive carcinoma of the breast. Appl Immunohistochem 1997; 5:141-151.

30 Werling RW, Hwang H, Yaziji H, et al. Immunohistochemical distinction of invasive from noninvasive breast lesions: a comparative study of p63 vs calponin and smooth muscle myosin heavy chain. Am J Surg Pathol 2003;27:82-90. 